Contents lists available at Journal Redwhitepress
Journal of Educational and Learning Studies
JiSSN: 2655-2760 (Print) ISSN: 2655-2779 (Electronic)
Journal homepage: http://iournal.redwhitepress.com/index.php/iles

\title{
E-learning to m-learning: are the politeknik malaysia's lecturers ready for the transition?
}

\author{
Ilya binti Ismail ${ }^{1}$, Noor Azlina binti Ahmad ${ }^{2}$, Suriah binti Mohamad ${ }^{3}$, \\ ${ }^{1}$ Electrical Engineering Department, Politeknik Sultan Salahuddin Abdul Aziz Shah, Selangor, Malaysia \\ ${ }^{2}$ Mechanical Engineering Department, Politeknik Nilai, Negeri Sembilan, Malaysia \\ ${ }^{3}$ Civil Engineering Department, Politeknik Port Dickson, Negeri Sembilan, Malaysia
}

\section{Article Info \\ Article history: \\ Received Aug 20th, 2020 \\ Revised Oct 24th, 2020 \\ Accepted Oct 28th, 2020}

\section{Keyword:}

Readiness

Mobile learning

E-learning

Post-COVID19

\begin{abstract}
The rapid development of 4IR in Malaysia has revolutionized the way of learning. Whole world is promoting electronic learning (e-Learning) as a new method to enhance the learning activities. The campaign continues to hike up when the world was shaken by the COVID19 pandemic, which caused most of the learning centre to close and force classes to be implemented completely online. Hence, this situation introduces the style of studying through mobile phone using the internet known as m-Learning. Although those two styles has been introduced for some time now at Politeknik Malaysia, there is no research conducted to measure the readiness of e-Learning and m-Learning within its context. As such, the aim of this study is to assess the lecturers' readiness in two politeknik namely; Politeknik A and Politeknik B. A total of 140 respondents were collected from using an online survey. A five-point Likert scale that demonstrated degrees of the agreement was applied to capture the lecturers' perceptions on their readiness for these two style learning. The results attained from this particular assessment can be used as some sort of guidelines for further development of e-Learning environment in Politeknik Malaysia.
\end{abstract}

C 2020 The Authors. Published by Redwhitepress.

This is an open access article under the CC BY-NC-SA license (https://creativecommons.org/licenses/by-nc-sa/4.0/

\section{Corresponding Author:}

Ilya binti Ismail

Electrical Engineering Department, Politeknik Sultan Salahuddin Abdul Aziz Shah, Selangor, Malaysia

Email: ilyaismail86@gmail.com

\section{Introduction}

The empire of digitalism has created a borderless state that allows information to be access anytime and anywhere. This advantage gives the world of education a broad and wider knowledge sharing. Along in the growing of ICT Empire, the teaching and learning trend began to shift from traditional board to electronic learning (e-learning), then to mobile learning (m-learning). E-learning is the broader concept of applying digital and Internet technology in education. In other words, according to (Heinich, Molenda, Russell, \& Smaldino, 2012), eLearning, "is Internet-based learning. The institutions can include a networked community of learners, content developers, team management of the learning experience with the experts and content delivery in multiple different formats. E-learning is accountability for all participants in the learning process, increased access to learning materials, and provides faster learning at reduced costs.

The pandemic COVID19 that shook the whole world speed up the pace of transition, when most of the education institutions force to conduct classes by online. Every academician and learners prefer to use mlearning since hand phone is nowadays necessities. Students are more motivate and engage throughout the $\mathrm{m}$ learning tools (Ariffin, 2011) such as kahoot and powtoon. The current learning process tends to emphasize more on the teaching process, based on the content base, and targeting large of student groups. However, are 
the lecturers ready for the transition? Since there are many additional gadgets, skill and cost have to be spent in order to ensure they are digital literacy.

E-learning readiness (ELR) is defined as the mental or physical readiness of an organization for a learning experience (Borotis \& Poulymenakou, 2009). Measurement of readiness of e-learning implementation is needed to know the condition and suitability of institutional strategy compared with ideal condition expected. Hence, this study aims to identify the level of readiness of online teaching and learning (PdPDT) of Malaysia's politeknik lecturers covering internet readiness, equipment and software support, content and training and also to seek the lecturers opinion in order to identify the level of readiness and commitment of the organization and the management of the institution.

To measure the perceived usefulness and ease-of-use among these technology handler, Davis (1989) developed the Technology Acceptance Model (TAM). (Hsiu Mei Huang \& Liaw, 2005) stated that the goal of Davis's classic TAM is to explain individuals' use of a specific system under organizational settings. TAM is a widely used theory among several models in the information system literature to explain individuals' acceptance of information technology. According to (Masrom, 2007), when consumers are ready with a new software package, TAM suggests them that numerous numbers of factors influence their decision regarding the process and the time of using it. (Bagozzi, Davis, \& Warshaw, 1992) stated that TAM predicts an individual forms an intention to act, and that the individual will be free to act without constraint; though, in the real world, there will be several limitations, such as limited abilities, time constraints, organizational or environmental limits, or unconscious habits, which limit the freedom to act.

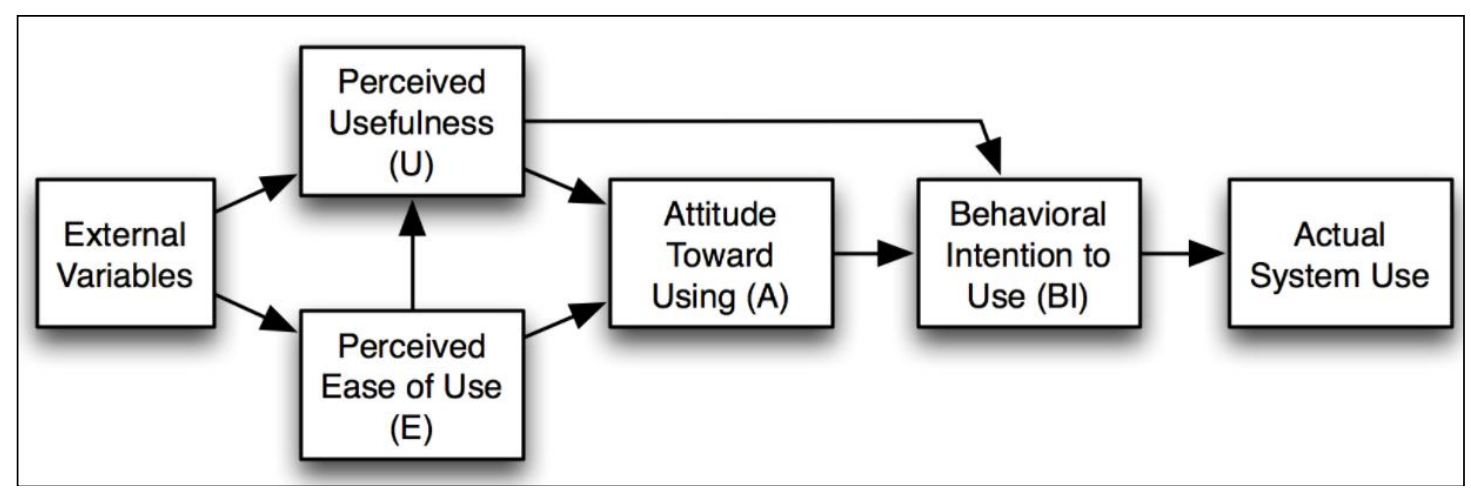

Figure $1<$ The Technology Acceptance Model, Version 1>

(Source: Davis, Bagozzi \& Warshaw: 1989)

The importance and the rationale of this research lie in the identification and analyses of the trends related to the readiness of Malaysia's politeknik lecturers to use digital technologies in their academic processes. The research results can be use as an important input to the design of new academic programs that would be compatible with the emerging trends in the field of digital technologies

\section{Method}

Quantitative method applied for data collection which may emphasize objective measurement and statistical, mathematical, or numerical analysis of data collected through opinion polls, questionnaires, and surveys, or by manipulating existing statistical data using computational techniques (Muijs 2010). This survey presumes to have an objective approach to studying research problems, where data is controlled and measured, to address the accumulation of facts, and to determine the causes of behaviour. Consequently, the results of quantitative research may be statistically significant but are often humanly insignificant. Quantitative research focuses on the collection of numerical data and generalizing it among groups of people; or to explain specific phenomena (Babbie, 2012) that is suitable according to this research objective.

In this study, survey research method is use for collecting data by using questionnaire as the main instrument. This method is suitable for reviewing the relationship between dependent variables and independent variables. The variables reviewed can be categorize into several dimensions.

Another factor that drive the selection of survey methods is that the researchers does not have the authority to make control of the activities or the practices implemented in the institution. All planning, facilities, and other matters related to the culture of innovation are beyond the control of the researchers. Another factor that supports the selection of this method is that polytechnic lecturers who take this course are 
numerous and scattered. Therefore, the survey method is very suitable to use. The survey study used a series of questionnaire as the main research instrument.

Reliability in quantitative methods refers to the ability of a study to obtain similar values when the same measurement is repeat for example; the extent to which the consistency of the instrument has the same effect when it is used at different times, locations, or populations (Drost 2011). According to Taber (2018), Alpha Cronbach is for testing the reliability of internal consistency. 'Likert scale is commonly used in many affective instruments. If numbers are use to represent reaction choices, analysis for internal consistency can be performed using Cronbach's alpha (McNeish \& Dumas, 2018). Table below show the link between ten models ELR showing the popular factors among the research.

Table $1<$ Mapping E-Learning Readiness (ELR) Factor>

\begin{tabular}{|c|c|c|c|c|c|c|c|c|}
\hline ELR Factors & $\begin{array}{c}\text { Chapnick } \\
(2000)\end{array}$ & $\begin{array}{c}\text { Engholm } \\
\text { (2001) }\end{array}$ & $\begin{array}{l}\text { Haney } \\
(2002)\end{array}$ & $\begin{array}{c}\text { Kaur } \\
\& \\
\text { Abas } \\
(2004)\end{array}$ & $\begin{array}{c}\text { Swatman } \\
\text { \& So } \\
(2005)\end{array}$ & $\begin{array}{c}\text { Psycharis } \\
(2005)\end{array}$ & $\begin{array}{c}\text { Akaslan } \\
\& \\
\text { Effie } \\
(2011)\end{array}$ & $\begin{array}{c}\text { Seakow } \\
\& \\
\text { Samson } \\
(2011)\end{array}$ \\
\hline Psychological & $\sqrt{ }$ & $\sqrt{ }$ & $\sqrt{ }$ & & $\sqrt{ }$ & & & \\
\hline Sociological & $\sqrt{ }$ & & & & $\sqrt{ }$ & & & \\
\hline Environmental & $\sqrt{ }$ & & & $\sqrt{ }$ & $\sqrt{ }$ & & & \\
\hline $\begin{array}{l}\text { Human } \\
\text { Resource }\end{array}$ & $\sqrt{ }$ & & $\sqrt{ }$ & $\sqrt{ }$ & & $\sqrt{ }$ & $\sqrt{ }$ & $\sqrt{ }$ \\
\hline Financial & $\sqrt{ }$ & & $\sqrt{ }$ & $\sqrt{ }$ & & $\sqrt{ }$ & & $\sqrt{ }$ \\
\hline $\begin{array}{l}\text { Technological } \\
\text { Skill }\end{array}$ & $\sqrt{ }$ & $\sqrt{ }$ & & & $\sqrt{ }$ & $\sqrt{ }$ & & $\sqrt{ }$ \\
\hline Equipment & $\sqrt{ }$ & & & & & & $\sqrt{ }$ & $\sqrt{ }$ \\
\hline $\begin{array}{l}\text { Content } \\
\text { Innovat ion }\end{array}$ & $\sqrt{ }$ & $\sqrt{ }$ & & $\sqrt{ }$ & & $\sqrt{ }$ & $\sqrt{ }$ & \\
\hline $\begin{array}{l}\text { Institution } \\
\text { Leadership }\end{array}$ & & $\sqrt{ }$ & $\sqrt{ }$ & $\sqrt{ }$ & $\sqrt{ }$ & $\begin{array}{l}\sqrt{ } \\
\sqrt{ }\end{array}$ & $\sqrt{ }$ & $\sqrt{ }$ \\
\hline Culture & & $\sqrt{ }$ & $\sqrt{ }$ & & & $\sqrt{ }$ & & \\
\hline Policy & & & $\sqrt{ }$ & & $\sqrt{ }$ & & & $\sqrt{ }$ \\
\hline
\end{tabular}

It is important to always provide sufficient information to allow other researchers to adopt or replicate the methodology. This information is particularly important when a new method has been developed or an innovative use of an exisiting method is utilized. The questionnaire were craft to fulfill the the ELR model and Technology Acceptance Model (TAM) considering five dimensions; namely training, support from institutions, culture, technology and content readiness..

\section{Results and Discussions}

Overall, this study is a single-shot Internet survey using a self-report questionnaire. Descriptive statistics and frequency tables and cross tabulation tables generate to present the results to the research questions. The survey includes seven subgroups of questions, which relate to definitions of terms, background information, eLearning, the expectations of eLearning with traditional learning, digital devices, learning management systems, as well as Massive Open Online Courses (MOOCs).

The survey was distributed to 140 lecturers. During the phase of data collection, reminders were sent out to the 5000 potential respondents to complete the survey. There were 183 responses to the online survey including 43 responses with missing data. The first stage was to clean the data. By excluding those 43 responses, 140 responses were actually used for the data analysis. This represents a response rate of just over $5 \%$. This situation similar with (Nulty, 2008) where stated that it is well known that survey response rates have been diminishing for years

Linear regression is used to analyze the relationship of dependent and independent variables. The independent variables are studied whether they are factors that affect the dependent variables. Table 1 is the effect size of the independent variable on the dependent variable.

The results of regression analysis in table 4, show that institutional support variables are not significant in providing readiness transition from mlearning to elearning and to be conducted by lecturers. On the other 
hand, the variables of content, technology, culture and training have a significant impact on the availability of online learning to be implemented by lecturers

Table 2 <Correlation Analysis>

\begin{tabular}{clccc}
\hline Dependent Variable & Independent Variable & Nilai r & $\begin{array}{c}\text { Significance/ } \\
\text { Insignificance }\end{array}$ & $\begin{array}{c}\text { Correlation } \\
\text { level }\end{array}$ \\
\hline \multirow{5}{*}{ Readiness } & Content & 0.62 & Significance & moderate \\
\cline { 2 - 5 } & Technology & 0.62 & Significance & moderate \\
\cline { 2 - 5 } & Culture & 0.68 & Significance & moderate \\
\cline { 2 - 6 } & $\begin{array}{l}\text { Support from } \\
\text { Institution }\end{array}$ & 0.54 & Significance & moderate \\
\cline { 2 - 5 } & Training & 0.61 & Significance & moderate \\
\hline
\end{tabular}

Table 3 <Readiness Level Based on Regration Test>

\begin{tabular}{llc}
\hline Coofficients & Mean Range & Readiness Level \\
\hline$\beta$ & Under 0.05 & Very low \\
\cline { 2 - 3 } & $0.05-0.30$ & low \\
\cline { 2 - 3 } & $0.31-0.50$ & moderate \\
\cline { 2 - 3 } & More than 0.5 & high \\
\hline
\end{tabular}

Table $4<$ Regration Analysis $>$

\begin{tabular}{clccccc}
\hline Dependent Variable & $\begin{array}{l}\text { Independent } \\
\text { Variable }\end{array}$ & $\begin{array}{l}\text { Unstandardized } \\
\text { Coofficients (B) }\end{array}$ & $\begin{array}{c}\text { Standardized } \\
\text { Coofficients } \\
\text { (Beta) } \beta\end{array}$ & $\mathrm{t}$ & $\begin{array}{c}\text { Significance/ } \\
\text { Insignificance }\end{array}$ & $\begin{array}{c}\text { Readiness } \\
\text { Level }\end{array}$ \\
\hline \multirow{5}{*}{ Readiness } & Content & 0.34 & 0.22 & 10.8 & Significance & Small \\
\cline { 2 - 7 } & Technology & 0.16 & 0.17 & 7.2 & Significance & Small \\
\cline { 2 - 7 } & Culture & 0.32 & 0.31 & 12.59 & Significance & Moderate \\
\cline { 2 - 7 } & $\begin{array}{l}\text { Support } \\
\text { from }\end{array}$ & 0.01 & 0.04 & 0.23 & Unsignificance & Null \\
& Institution & & & & & \\
\cline { 2 - 5 } & Training & 0.35 & 0.22 & 10.4 & Significance & Small \\
\hline
\end{tabular}

Correlation Analysis for Level of Readiness

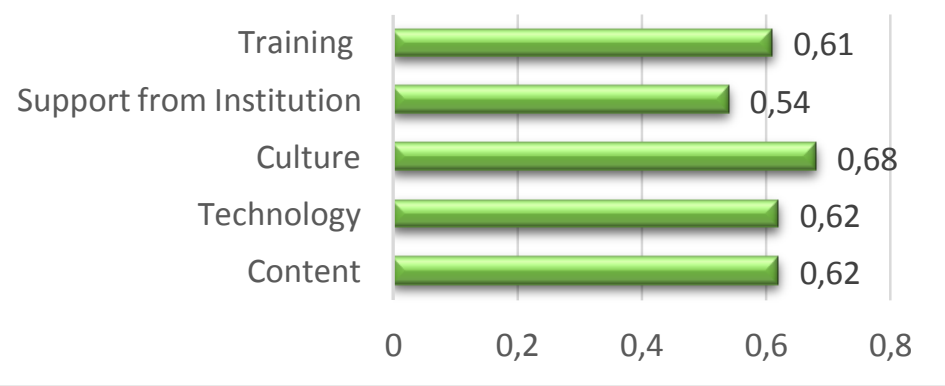

Figure $2<$ Readiness Level to Embracing Online Learning $>$

Based on Figure 1 shows the culture variable affects 31 percent on the availability of online teaching and learning implementation, followed by training and content affects 22 percent on the availability of teaching and learning implementation and Technology affects 17 percent on the availability of teaching and learning that conducted online. 


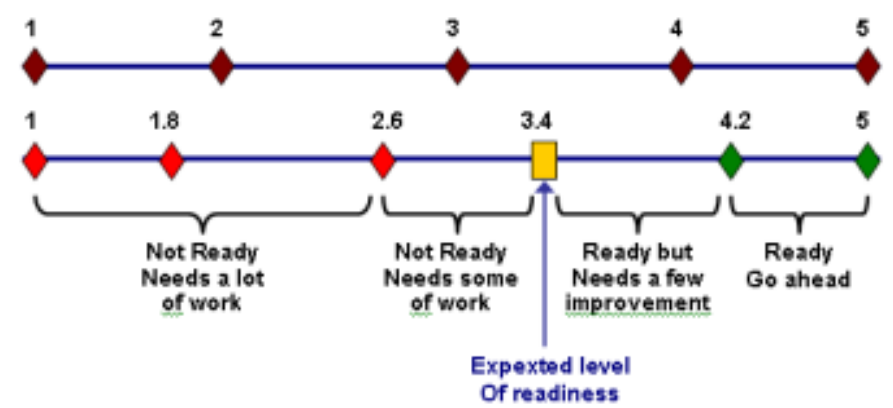

Figure 3 <Measurement Scale of Model ELR> (Aydin \& Tasci : 2005)

\section{Conclusions}

The findings in this study provide evidence to confirm some scholars' previous research findings. More efforts need to be made in order to improve the quality of eLearning courses in this, and perhaps other higher education institutions. Educators need to conduct further research on learning behaviors and consider students' learning needs in order to improve the efficiency of eLearning as continuing growth eLearning in higher education institutions is taking place.

\section{References}

Adiyarta, K., Napitupulu, D., Rahim, R., Abdullah, D., \& Setiawan, M. I. (2018). Analysis of e-learning implementation readiness based on integrated elr model. Journal of Physics: Conference Series, 1007(1). https://doi.org/10.1088/1742-6596/1007/1/012041

Ariffin, S. A. (2011). Mobile Learning in the Institution of Higher Learning for Malaysia students : Culture Perspectives. International Journal on Advanced Science, Engineering and Information Technology, 1(3), 283. https://doi.org/10.18517/ijaseit.1.3.59

Babbie, E. (2012). The Practice of Social Research. Wadsworth Cengage Learning (Vol. 66).

Bagozzi, R. P., Davis, F. D., \& Warshaw, P. R. (1992). Development and Test of a Theory of Technological Learning and Usage. Human Relations, 45(7), 659-686.

Muijs, D. (2010). Doing quantitative research in education with SPSS. Sage.

Borotis, S., \& Poulymenakou, A. (2009). E-learning acceptance in workplace training: The case of a Greek bank. 17th European Conference on Information Systems, ECIS 2009.

Heinich, R., Molenda, M., Russell, J., \& Smaldino, S. (2012). Instructional Media and Technology for Learning. International Journal of Distributed and Parallel Systems, 3, 8.

Hsiu Mei Huang, \& Liaw, S. S. (2005). Exploring users' attitudes and intentions toward the web as a survey tool. Computer in Human Behaviour, 21(5), 729-743.

Masrom, M. (2007). Technology acceptance model and E-learning. 12th International Conference on Education, (May), 21-24.

Drost, E. A. (2011). Validity and reliability in social science research. Education Research and perspectives, 38(1), 105.

Taber, K. S. (2018). The use of Cronbach's alpha when developing and reporting research instruments in science education. Research in Science Education, 48(6), 1273-1296.

McNeish, D., \& Dumas, D. (2018). Calculating Conditional Reliability for Dynamic Measurement Model Capacity Estimates. Journal of Educational Measurement, 55(4), 614-634.

Nulty, D. D. (2008). The adequacy of response rates to online and paper surveys: What can be done? Assessment and Evaluation in Higher Education, 33(3), 301-314. https://doi.org/10.1080/02602930701293231

Aydin, C. H., \& Tasci, D. (2005). Measuring Readiness for e-Learning: Reflections from an Emerging Country. Educational Technology \& Society, 8 (4), 244-257. 